Reprod. Nutr. Dévelop., 1984, 24 (5A), 563-585.

\title{
Organogenèse et cytodifférenciation de la prostate de l'Escargot Helix aspersa Müller
}

\author{
J. ENÉE, L. GOMOT
}

Laboratoire de Zoologie et Embryologie,

E.R.A. CNRS n'071049, Faculté des Sciences,

Place Maréchal Leclerc, 25030 Besançon Cedex, France.

\begin{abstract}
Summary. Organogenesis and cytodifferentiation of the prostate gland of the snail, Helix aspersa Müller.

Organogenesis of the prostate gland of the pulmonate stylommatophora, Helix aspersa Müller, has been divided into four stages which culminate in a tubular structure with branched diverticula connected to the male portion of the spermoviduct.

Electron microscopic observations revealed the differentiation of undifferentiated epithelial cells into two cell types : glycogen-storing ciliated cells and secretory cells. The differentiation of glandular cells was characterized by the appearance of numerous lipid droplets and the prominent development of granular ER and the Golgi apparatus. Prosecretion granules (or post-Golgi sacs) left the maturing face of the dictyosome and were transformed into heterogeneous phospholipo-protein granules.
\end{abstract}

\section{Introduction.}

Dans la classe des Gastéropodes, la prostate revêt de multiples aspects selon les groupes (Creek, 1951 ; Beeman, 1970; Duncan, 1975 ; Houston, 1976 ; Guyomarch-Cousin, 1976). Chez les Pulmonés Stylommatophores, elle se dispose généralement en un bourrelet arrondi, allongé le long du spermoviducte (Baudelot, 1863 ; Dubrueil, 1873 ; Rouzaud, 1885 ; Baecker, 1932 ; Visser, 1977) et présente une structure tubuleuse, souvent ramifiée (Yung, 1911 ; Filhol, 1938 ; Goddard, 1960 ; Breucker, 1964).

Les travaux histologiques (Holm, 1946 ; Abdel Malek, 1954a, b ; Smith, 1965) et ultrastructuraux (Bailey, 1973; De Jong-Brink, 1969, 1973 ; Quattrini, 1966a, b, 1967a, b ; Quattrini et Fondi, 1969) révèlent que la prostate de la plupart des Gastéropodes est constituée de cellules ciliées intercalées entre un ou plusieurs types de cellules sécrétrices. Les études histochimiques (Rangarao, 1963 ; Kugler, 1965 ; Plesch et al., 1971; Nanaware et Varute, 1976) et biochimiques (Bayne, 1967 ; Veldhuijzen et Van Beek, 1976) montrent que les tissus prostatiques se caractérisent par une faible mise en réserve de polysaccharides et une constitution fondamentalement protéique. 
Les données sur les aspects du développement de cette glande concernent principalement les Limaces (Lusis, 1961 ; Smith, 1966 ; Runham et Laryea, 1968) et un Prosobranche gonochorique, Littorina littorea (Herlin, 1980).

Nos observations sur la biologie du développement et de la reproduction de l'Escargot Helix aspersa avaient permis d'établir une relation entre les étapes de la croissance et la différenciation sexuelle de cet animal (Enée, 1980 ; Gomot et Enée, 1980). Au cours de la différenciation sexuelle, les changements de l'appareil génital sont continus et progressifs (Enée et Griffond, 1983) et jusqu'à présent, les études ont porté surtout sur la gonade (Guyard, 1971 ; Griffond et Bride, 1981) et sur la glande à albumen (Courtot et Gomot, 1982). Pourtant, l'une des premières glandes annexes à se constituer est la prostate (Enée et al., 1977). Aussi, nous at-il paru important de préciser les étapes de l'organogenèse et de dégager les caractères histochimiques et ultrastructuraux des cellules sécrétrices de cette glande associée à la gouttière qui conduit les spermatozoïdes.

\section{Matériel et méthodes.}

Matériel. - Les Escargots Helix aspersa Müll, utilisés pour l'expérimentation proviennent de l'élevage du laboratoire. La méthode d'obtention et d'incubation des pontes a déjà été décrite (Enée et Griffond, 1983) ainsi que les conditions d'élevage des jeunes animaux (Gomot et Enée, 1980). Sur un lot de 245 Escargots prélevés dans 8 pontes différentes et élevés jusqu'à la maturité sexuelle ( 8 à 9 mois), 5 à 10 animaux ont été sacrifiés chaque mois pour effectuer les fixations.

Techniques. - Le spermoviducte ou des fragments de prostate sont fixés pendant 1 à 2 heures à $4^{\circ} \mathrm{C}$ dans une solution de glutaraldéhyde à $2 \%(200$ mOsM) tamponnée par le cacodylate de sodium $(0,1 \mathrm{M}, 200 \mathrm{mOsM})$; la pression osmotique du fixateur est ajustée avec $\mathrm{NaCl}(0,17 \mathrm{M}, 350 \mathrm{mOsM})$. Après plusieurs lavages à $4{ }^{\circ} \mathrm{C}$ dans le mélange (tampon cacodylate $0,1 \mathrm{M}$ à $200 \mathrm{mOsM} ; \mathrm{NaCl}$ $0,16 \mathrm{M}$ à $300 \mathrm{mOsM} ; 1: 1)$, les pièces subissent une heure de post-fixation au tétroxyde d'osmium à $2 \%(80 \mathrm{mOsM})$ tamponné par le cacodylate de sodium 0,2 $\mathrm{M}$ à $400 \mathrm{mOsM}$ ( $\mathrm{PO}$ finale $=240 \mathrm{mOsM}$ ) à température ambiante. Après déshydratation selon la méthode de Luft (1961), les inclusions sont réalisées dans le mélange épon-araldite utilisé par Anderson et Ellis (1965) en ramenant la proportion de DMP (*) 30 à $1,7 \%$ au lieu de $4 \%$, suivant la méthode de Mollenhauer (1964).

Les coupes semi-fines de $0,5 \mu \mathrm{m}$ à $2 \mu \mathrm{m}$ d'épaisseur, récupérées sur lames de verre, permettent une étude histologique et histochimique. Nous avons effectué diverses colorations :

- au "Stains all " pH 5,4 et 2,8 selon Green et Pastewka (1974), après élimination du milieu d'inclusion avec une solution saturée de soude alcoolique selon la méthode de Lane et Europa (1965);

- au bleu de toluidine selon Trump et al. (1961);

$\left.{ }^{*}\right) \mathrm{DMP}=2,4,6$,-tri (diméthylaminométhyl) phénol. 
- à I'APS-bleu de toluidine d'après Cardno et Steiner (1965) ;

- au Noir Soudan B d'après McGee-Russel et Smale (1963).

Les coupes ultrafines sont contrastées à l'acétate d'uranyle à 3-4\% dans l'alcool $50^{\circ}$, puis au citrate de plomb selon Reynolds (1963). La mise en évidence des polysaccharides est réalisée sur coupes fines montées sur des grilles en or et traitées selon la technique à l'acide périodique-thiocarbohydrazide-protéinate d'argent d'après Seligman, modifiée par Thiery et Rambourg (1974).

\section{Résultats.}

1. Stade de l'ébauche prostatique (phase infantile). - Chez des animaux âgés de deux mois, sur des coupes transversales de spermoviductes isolés, on observe, à un niveau donné, une évagination de l'épithélium qui constitue l'ébauche d'un tubule prostatique (PI. I, fig. 1). Des coupes sériées montrent que plusieurs évaginations épithéliales prennent naissance sur toute la longueur du canal mixte. Chacune de ces formations se caractérise par sa continuité épithéliale. Les divisions cellulaires se poursuivent au niveau de l'épithélium du spermoviducte et également au sein de l'évagination primitive. Les noyaux des cellules du spermoviducte conservent leur forme allongée, par contre, quelques noyaux des cellules engagées dans l'ébauche de la prostate commencent à s'arrondir.

En microscopie électronique, les cellules épithéliales du spermoviducte présentent le même aspect que celui décrit à un mois (Enée et Griffond, 1983). Cependant, les cellules sont plus hautes $(12$ à $18 \mu \mathrm{m})$, les plages de glycogène sont beaucoup plus importantes, surtout dans la zone apicale, et elles sont associées à des gouttelettes lipidiques plus nombreuses. Cet aspect cellulaire se retrouve dans l'évagination de l'épithélium, ébauche de la prostate, au stade initial de cette formation. Notons que les desmosomes latéraux et les hémidesmosomes existant entre les cellules épithéliales indifférenciées du spermoviducte et la lame basale sous-jacente sont observés moins fréquemment au niveau de l'épithélium prostatique. Ensuite, le hyaloplasme des cellules épithéliales de la prostate s'éclaircit, le glycogène est toujours présent, mais la forme en rosette n'est plus dominante. De plus, dans certaines cellules de l'ébauche, le noyau s'arrondit et occupe la région basale de la cellule (PI. I, fig. 2). Le nucléoplasme est envahi d'hétérochromatine en mottes "effilochées", tandis que la chromatine périphérique est plus fine. Quelques lames d'ergastoplasme se développent dans la zone péri-nucléaire ; les ribosomes sont répartis très irrégulièrement sur les membranes du réticulum et sur la membrane externe de l'enveloppe nucléaire. L'appareil de Golgi présente un réseau dilaté du côté de la face de formation et il comprend 5 à 6 saccules qui émettent des vésicules à leur extrémité. Des saccules de la face de maturation s'isolent du dictyosome et se dilatent en donnant naissance aux granules de prosécrétion.

2. Stade d'apparition de la sécrétion - Début de la dichotomisation des tubes (phase infantile). - Chez des Escargots âgés de trois mois, les évaginations primaires deviennent plus nombreuses et chacune s'allonge et s'enfonce dans le 
tissu mésenchymateux environnant dont les cellules commencent à s'orienter pour former un premier pli dans la lumière du spermoviducte (PI. I, fig. 3). A partir d'une évagination initiale naissent des tubules prostatiques secondaires dans lesquels on remarque certaines cellules à noyau rond et très volumineux qui commencent à élaborer des globules de sécrétion. Dans ces tubules, on trouve fréquemment une ou deux cellules dans une phase de sécrétion plus avancée.

En ultrastructure, on remarque que le mésenchyme qui entoure les tubules prostatiques soutient également un gros nerf, vraisemblablement une branche du nerf intestinal située à proximité de l'artère génitale ou artère utérine majeure (Vosswinkel, 1976) ; des filets nerveux et des fibres musculaires s'infiltrent aussi entre les tubules. Parmi l'ensemble des cellules de ces premiers tubules de la prostate qui conservent leur aspect épithélial, on retrouve les cellules avec un noyau plus ou moins arrondi qui présentent quelques grains de sécrétion. D'autres cellules, à noyau allongé, sont probablement à l'origine du type cilié qui apparaît plus nettement dans les stades ultérieurs du développement (fig. 1, Texte).

(a)

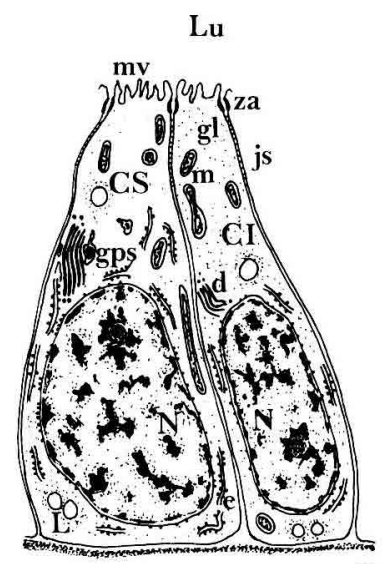

(b)

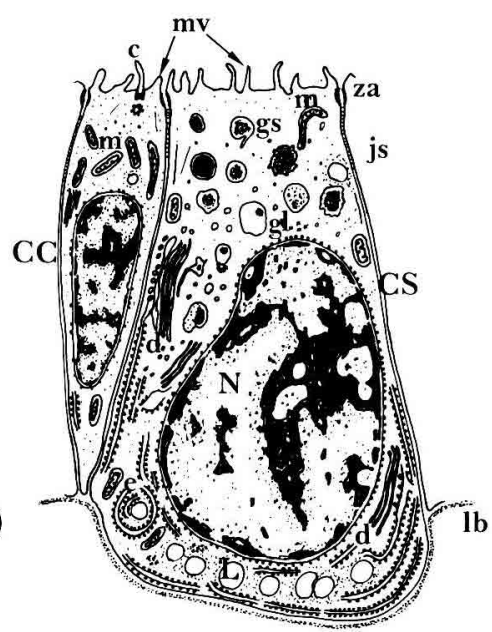

FIG. 1. - Texte. - Schémas des deux types de cellules constituant les tubules prostatiques au stade de l'ébauche (a) et au stade d'apparition de la sécrétion (b).

c: cil; $\mathrm{CC}$ : cellule ciliée; $\mathrm{Cl}$ : cellule épithéliale indifférenciée; $\mathrm{CS}$ : cellule sécrétrice; $\mathrm{d}$ : dictyosome ; e : ergastoplasme ; gl : glycogène; gps : granules de prosécrétion; gs : grains de sécrétion; js: jonction septée; $L$ : liposomes; $l b$ : lame basale ; $L u$ : lumière ; $m$ : mitochondries ; mv : microvillosités ; $\mathrm{N}$ : noyau ; za : zonula adherens.

Les premières cellules glandulaires deviennent volumineuses (17 à $24 \mu \mathrm{m}$ de haut) et s'étendent en direction du mésenchyme (PI. II, fig. 1). La surface apicale de ces cellules sécrétrices présente des microvillosités qui peuvent être très nombreuses ou au contraire rares. A cette extrémité des cellules et sur le quart de leur hauteur, les membranes latérales sont épaissies par des "zonula adherens » suivies de jonctions septées. La lame basale (PI. II, fig. 2) est très fine $(10 \mathrm{~nm})$. Le 
noyau est souvent polymorphe avant d'être ovale puis rond et volumineux. Le nucléoplasme est très riche en hétérochromatine condensée, celle-ci constitue de véritables plages qui apparaissent fenestrées.

La région basale de la cellule sécrétrice peut encore contenir du glycogène, présent en faible quantité près du noyau. De nombreuses gouttelettes lipidiques s'accumulent en position infra-nucléaire où l'ergastoplasme peut former des figures d'enroulement en empreintes digitales ou «whorls " (Rebhun, 1961; Marshall, 1973) qui ont été observées à un stade sensiblement identique dans la prostate d'Agriolimax reticulatus (Bailey, 1973). Au niveau de ces « onion bodies " , on remarque une communication étroite entre la cavité du réticulum et les gouttelettes de lipides (PI. II, fig. 3); dans ces dernières, des zones claires apparaissent et représenteraient l'emplacement d'un matériel utilisé pour la formation des membranes endoplasmiques (Singal et Sanders, 1974). Plusieurs nappes de réticulum endoplasmique granulaire se développent aussi le long des membranes latérales. Le réticulum lisse est peu abondant et se présente sous forme de petites vésicules rondes ou aplaties.

L'appareil de Golgi est représenté par plusieurs dictyosomes en position latérale ou supra-nucléaire. Sur la face de formation des dictyosomes, la coalescence de nombreuses vésicules de transition constitue le premier saccule qui apparaît très boursoufflé (PI. I, fig. 4). Sur la face de maturation, les saccules golgiens distaux s'isolent, d'autres se dilatent et sont à l'origine de la formation des petites vacuoles qui se transforment en granules de prosécrétion. La région golgienne est riche en vésicules lisses ou hérissées qui s'associent aux granules de prosécrétion.

Dès leur apparition, les grains de sécrétion sont très polymorphes. Ils possèdent tous une membrane limitante. Les granules de sécrétion localisés dans la région golgienne présentent le plus souvent un aspect vacuolaire. Les grains de petites tailles sont en général denses aux électrons, alors que les grains de sécrétion plus gros présentent un matériel moins homogène et moins dense ( $\mathrm{PI}$. II, fig. 4).

Les mitochondries sont réparties dans l'ensemble du hyaloplasme, elles sont parfois très longues et possèdent une matrice dense. Certaines mitochondries, de taille plus réduite, côtoient les enroulements du réticulum rugueux (PI. II, fig. 3). Des microtubules; orientés selon l'axe de la cellule sécrétrice, sont présents au sein du hyaloplasme, plus fréquemment le long des membranes latérales.

L'apparition précoce de la sécrétion ne concerne que quelques cellules de l'ébauche prostatique. La plupart des cellules épithéliales adjacentes ont conservé une charge en glycogène importante qui est dispersée dans le hyaloplasme sous forme d'unités $\beta$. Dans ces cellules ne présentant pas de grains de sécrétion, les mitochondries se regroupent dans la zone apicale. Dans cette même région, on observe assez fréquemment un diplosome dans une aire cytoplasmique riche en microtubules d'un diamètre de $18 \mathrm{~nm}$ ou un centriole et un cinétosome ( $\mathrm{PI}$. II, fig. 5). Ces cellules qui amorcent leur ciliogenèse, présentent également des microvillosités apicales. 

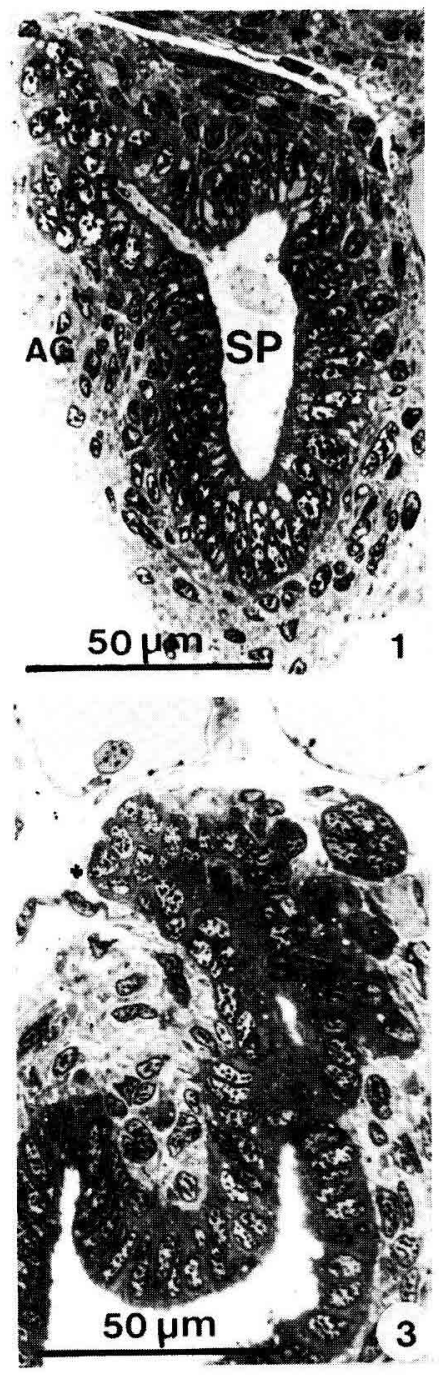

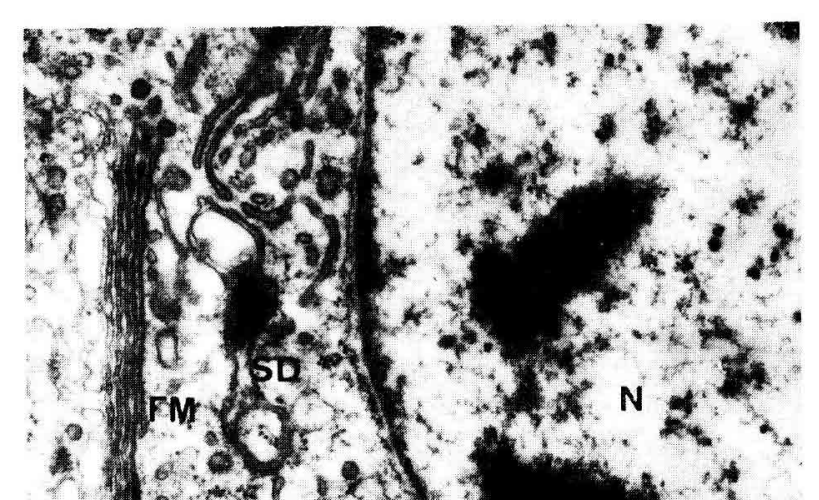

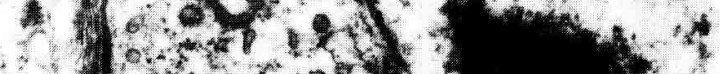

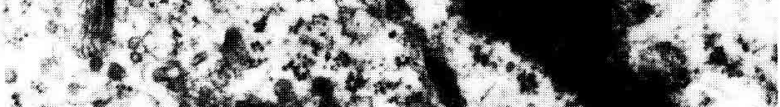

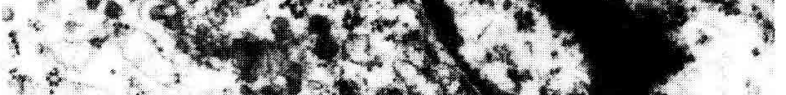

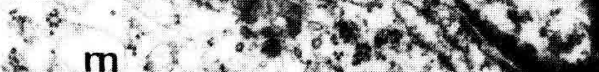

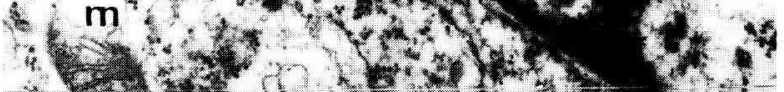

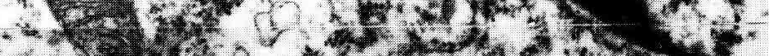

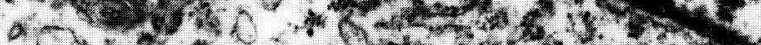

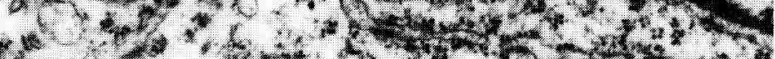

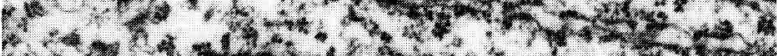

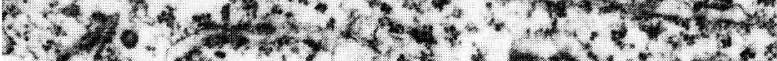

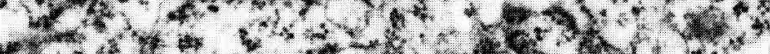

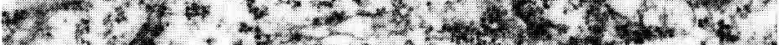

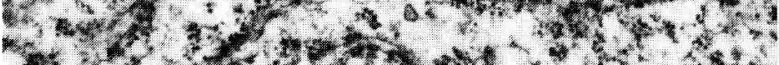

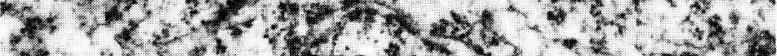

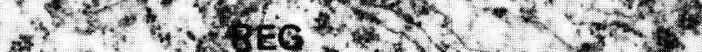

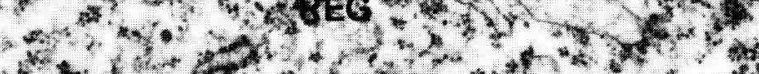

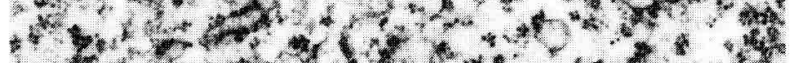

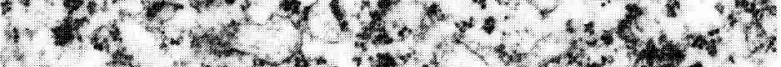

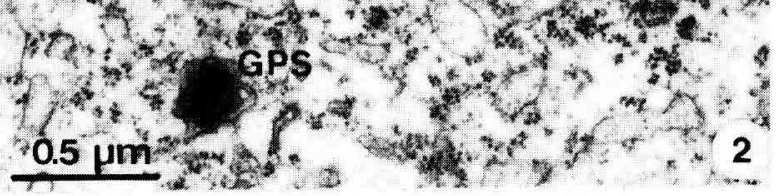

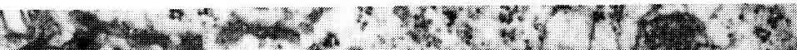

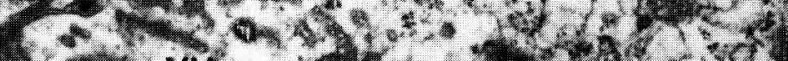

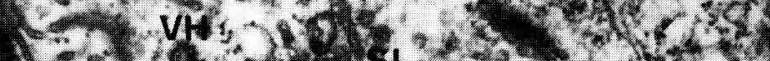

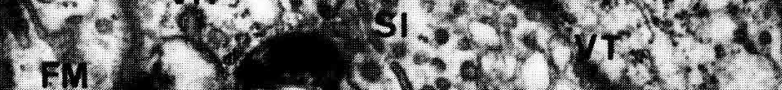

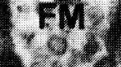

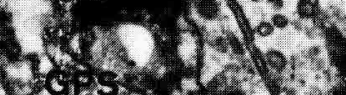

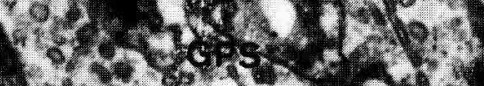

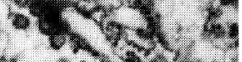

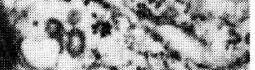

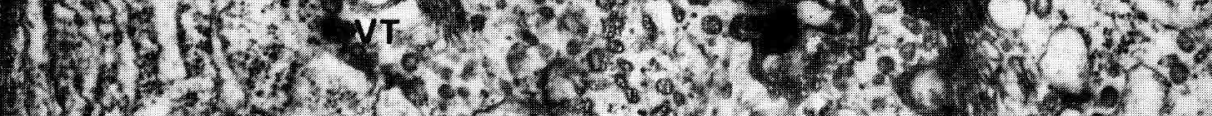

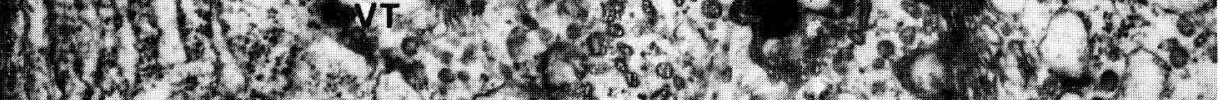

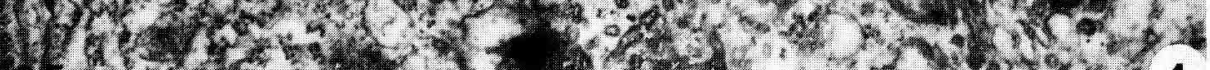

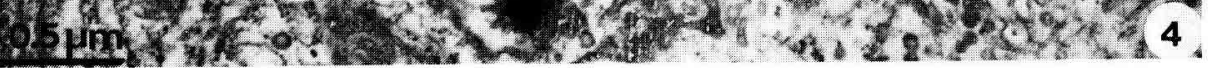


3. Stade tubulaire composé (phase juvénile). - Du $4^{\mathrm{e}}$ au $6^{\mathrm{e}}$ mois, le développement de la prostate est important (Enée et al., 1977) ; les tubules prostatiques continuent de se ramifier et s'allongent ; leur ensemble constitue un ruban glandulaire annexé à la gouttière mâle du canal mixte. Les évaginations primitives qui deviennent des formations tubuleuses principales sont revêtues d'un épithélium comprenant beaucoup plus de cellules ciliées, comparativement aux tubules secondaires qui présentent plus de cellules sécrétrices. Au cours de cette phase dite juvénile, le spermoviducte est donc essentiellement formé par la composante mâle que représente la prostate, dont un grand nombre de cellules entre en phase sécrétoire (PI. III, fig. 1). Le tissu vésiculeux, dont quelques cellules peuvent subsister entre les tubules de la glande (Sminia, 1972 ; Bani et Delfino, 1974), reste abondant autour de l'artère génitale.

En microscopie électronique, on reconnaît deux types cellulaires dans l'épithélium prostatique (PI. III, fig. 3 et fig. 2, texte) :

- les cellules non sécrétrices, intercalées entre les cellules sécrétrices, s'étendent de la lame basale à la lumière. Leur noyau, à hétérochromatine condensée, est très allongé. Le cytoplasme, chargé de glycogène, contient quelques gouttelettes lipidiques. L'apex de ces cellules possède quelques microvillosités et différencie des cils.

- les cellules sécrétrices d'une hauteur de 20 à $35 \mu \mathrm{m}$ possèdent, à la partie basale, un noyau ovale ou rond avec des masses importantes d'hétérochromatine

\section{PLANCHE I}

FIG. 1. - Ebauche prostatique (PR), évagination épithéliale du spermoviducte (SP) d'un animal âgé de 2 mois $(\varnothing=12,5 \mathrm{~mm})$ à proximité de l'artère génitale (AG). Coloration au bleu de toluidine.

FIG. 2. - Cytodifférenciation d'une cellule sécrétrice au sein de l'ébauche de la prostate. Les premières citernes de réticulum endoplasmique granulaire (REG) apparaissent dans le cytoplasme périnucléaire sans disposition régulière. Les ribosomes sont libres ou disposés irrégulièrement sur les membranes du réticulum et sur la membrane externe de l'enveloppe nucléaire. On distingue un dictyosome dont les saccules empilés sont bien rectilignes. Du côté de la face de maturation (FM), plusieurs saccules sont isolés ; un saccule dilaté (SD) présentant une inclusion dense se transforme en granule de prosécrétion (GPS).

$\times 30000$ $\mathrm{m}$ : mitochondrie ; $\mathrm{N}$ : noyau.

FIG. 3. - Apparition de la sécrétion (S) au niveau de l'évagination qui s'allonge et s'enfonce dans le mésenchyme entourant le spermoviducte d'un animal âgé de 3 mois $(\varnothing=13,5 \mathrm{~mm})$. Coloration au bleu de toluidine. mt : mitose.

FIG. 4. - Coupe transversale d'une cellule sécrétrice de la prostate d'un animal âgé de 3 mois $(\varnothing=14,5 \mathrm{~mm})$. Aspect très boursoufflé du premier saccule sur la face de formation (FF) des dictyosomes, en regard du réticulum rugueux. Bourgeonnement de nombreuses vésicules de transition (VT) alignées à l'extrémité des lames de réticulum endoplasmique granulaire (REG). Du côté de la face de maturation (FM), des saccules restent en contact avec les saccules empilés du dictyosome où des saccules isolés (SI) se fragmentent et donnent naissance aux granules de prosécrétion (GPS) auxquels s'associent des vésicules hérissées (VH).

$\times 25000$

Reproduction, Nutrition, Développement $n^{\circ} 5$ A 1984. -5 . 


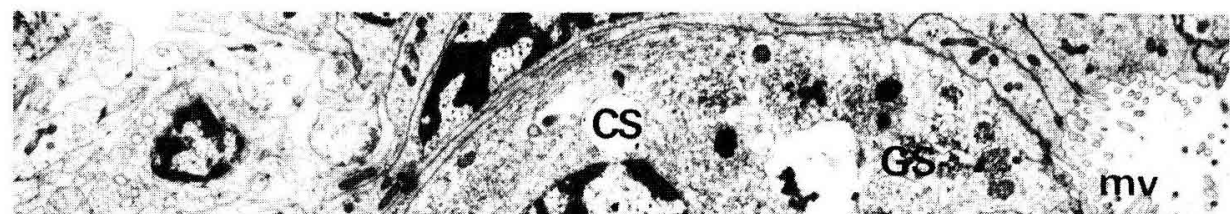

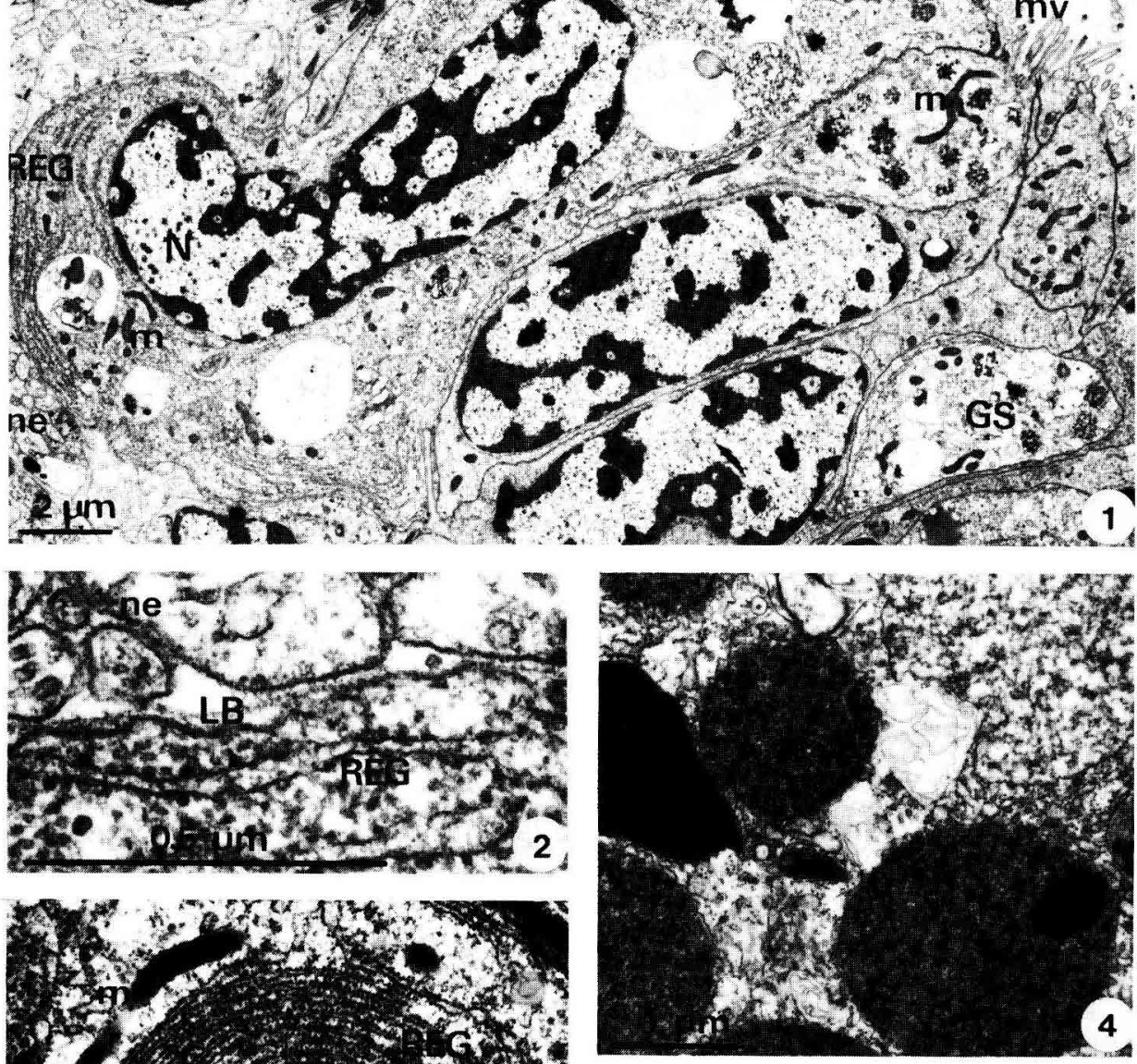
1.

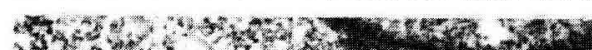
2.

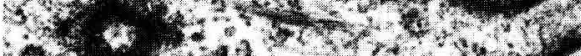

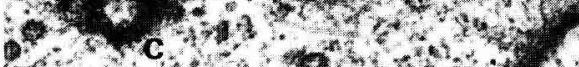
30.
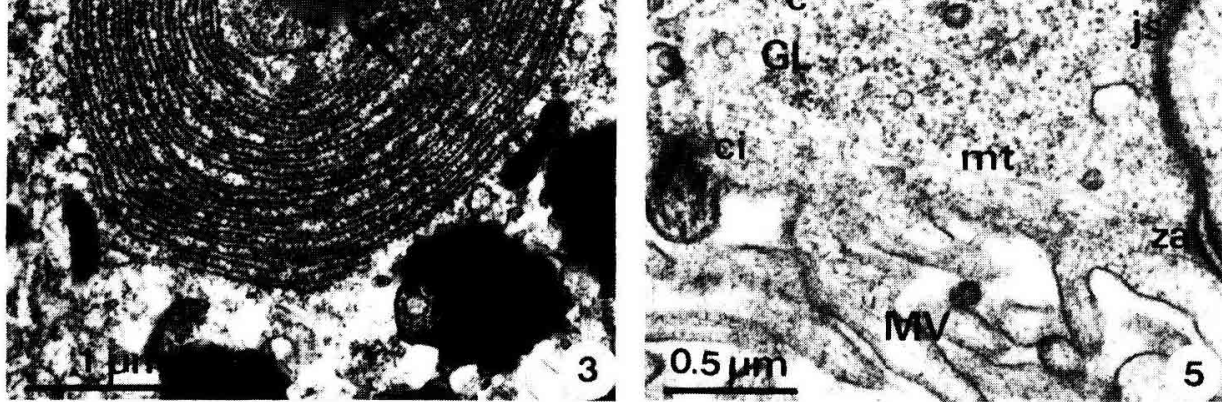
et de l'euchromatine dispersée et dense. Quelques petites inclusions très denses sont présentes dans le nucléoplasme (PI. III, fig. 3), celles-ci ressemblent à des granules périchromatiniens, car elles sont entourées d'un halo clair, mais leur taille (100 à $160 \mathrm{~nm}$ ) est trop importante pour les identifier à ces structures.

L'ergastoplasme, très développé sous forme de nappes parallèles, garnit toute la région périnucléaire et infranucléaire, où de nombreuses gouttelettes lipidiques (PI. III, fig. 2) sont associées ou non à des plages claires de glycogène. Le développement du réticulum endoplasmique granulaire se fait par un empilement de citernes très longues qui se prolongent le long des membranes latérales. L'ergastoplasme forme encore quelques figures d'enroulement et entoure des mitochondries; il se présente rarement sous forme de vésicules dilatées, hérissées de ribosomes. Quelques vésicules de réticulum lisse sont localisées au niveau du réseau tubulaire qui le relie au complexe golgien.

L'appareil de Golgi comprend plusieurs dictyosomes très allongés en position latérale ou supranucléaire. Chaque dictyosome est constitué de 5 ou 6 saccules contenant un matériel dense aux électrons. Sur la face de maturation, des granules de prosécrétion parfois fenestrés (PI. III, fig. 4) naissent d'une dilatation des parties fragmentées du dernier saccule golgien. Quelques vésicules hérissées sont présentes dans la région golgienne où les grains de sécrétion sont clairs. Ces derniers sont toujours pourvus d'une membrane et renferment une ou deux inclusions denses, d'aspect pseudocristallin. Des granules plus hétérogènes

\section{PLANCHE II}

Stade d'apparition de la sécrétion (animaux âgés de 3 mois. $\varnothing=14,5 \mathrm{~mm}$ )

FIG. 1. - Epithélium de la prostate; cellule sécrétrice (CS), au noyau riche en hétérochromatine très condensée, qui s'étend en direction du mésenchyme. Le cytoplasme renferme les premiers grains de sécrétion (GS).

$\mathrm{m}$ : mitochondrie ; mv : microvillosités ; $\mathrm{N}$ : noyau ; ne : nerf ;

$R E G$ : réticulum endoplasmique granulaire.

FIG. 2. - Pôle basal d'une ce/lule sécrétrice : celle-ci repose sur une lame basale (LB) qui est très mince à ce stade.

ne : nerf ; REG : réticulum endoplasmique granulaire.

$\times 80000$

FIG. 3. - Lamelles concentriques et aplaties de réticulum endoplasmique granulaire (REG) disposées autour d'une inc/usion lipidique. Relation de continuité (flèche) entre les cavités de l'ergastoplasme et la gouttelette de lipide.

$\times 18000$ $\mathrm{m}$ : mitochondrie.

FIG. 4. - Grains de sécrétion hétérogènes munis d'une membrane limitante festonnée.

$\times 14000$

FIG. 5. - Région apicale d'une cellule ciliée : formation d'un cil à partir d'un des centrioles. Les microvillosités (MV) sont courtes et irrégulières. Le cytoplasme est chargé de particules de glycogène $(\mathrm{GL})$ et de microtubules $(\mathrm{mt})$.

$\times 27000$ $\mathrm{c}$ : centriole ; ci : cinétosome ; js : jonction septée ; za : zonula adherens. 
remplissent entièrement la région cellulaire apicale. Ces grains de sécrétion, très denses, baignent dans le hyaloplasme riche en glycogène et en liposomes ; ceuxci sont quelquefois associés aux grains denses.

4. Stade de maturité (phase préadulte ou de maturité). - Après la puberté (6 mois), la prostate atteint son développement maximum, en raison d'une

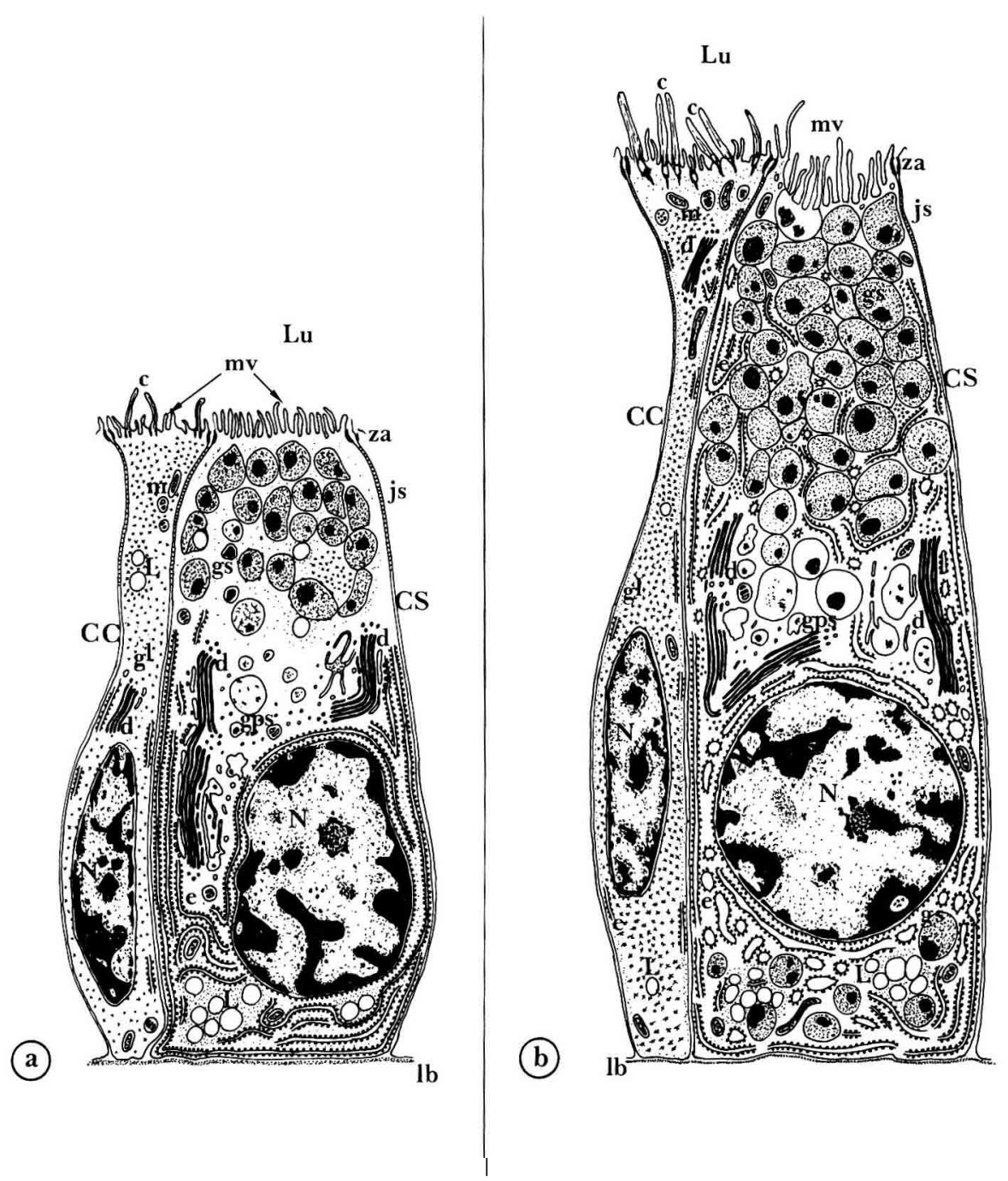

FIG. 2. - Texte. - Schémas des deux types de cellules constituant les tubules prostatiques au stade tubulaire composé (a) et au stade de maturité (b).

c : cil ; $\mathrm{CC}$ : cellule ciliée ; $\mathrm{Cl}$ : cellule épithéliale indifférenciée; $\mathrm{CS}$ : cellule sécrétrice ; $d$ : dictyosome ; e : ergastoplasme; gl : glycogène ; gps : granules de prosécrétion ; gs : grains de sécrétion; js: jonction septée; $\mathrm{L}$ : liposomes; $\mathrm{lb}$ : lame basale; $\mathrm{Lu}$ : lumière ; $\mathrm{m}$ : mitochondries ; $\mathrm{mv}$ : microvillosités ; $\mathrm{N}$ : noyau ; za : zonula adherens. 
accumulation importante de grains de sécrétion dans les cellules sécrétrices. Ce bourrelet glandulaire arrondi surmonte toute la région du spermiducte et s'épanche sur un côté surtout dans la région distale (fig. 3 , texte).

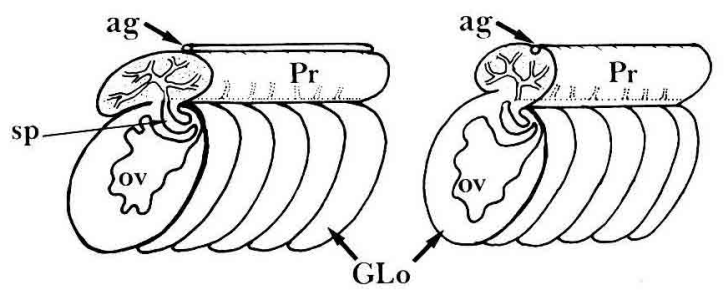

(a) région distale

région proximale

(b)

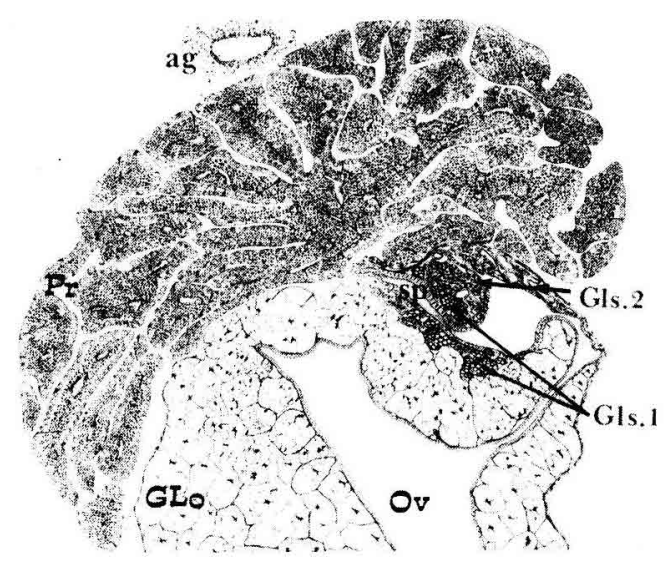

FIG. 3. - Texte. - Schéma général du spermoviducte $(a)(\times 2)$ et aspect de la prostate sur coupe transversale de spermoviducte (b) $(\times 10)$.

ag : artère génitale; GLo : glande de l'oviducte; Gls 1 : glande subépithéliale type $1 ;$ Gls 2 : glande subépithéliale type 2 ; Ov : oviducte ; Pr : prostate ; sp : spermiducte.

La poursuite de l'élaboration de globules de sécrétion jusqu'à son paroxysme augmente considérablement la hauteur des cellules sécrétrices qui atteint 50 $80 \mu \mathrm{m}$. Cette synthèse importante de grains de sécrétion s'accompagne de diverses modifications dans I'ultrastructure des cellules.

La région basale qui comprend encore des plages compactes de gouttelettes lipidiques au moment de la puberté, va être fortement perturbée par l'envahissement progressif des grains de sécrétion. Le réticulum endoplasmique granulaire dont les membranes sont tapissées de nombreux ribosomes, se présente fréquemment sous forme de vésicules dilatées dans la région infra et péri-nucléaire (PI. IV, fig. 1). Les cavités de I'ergastoplasme, au contenu finement 

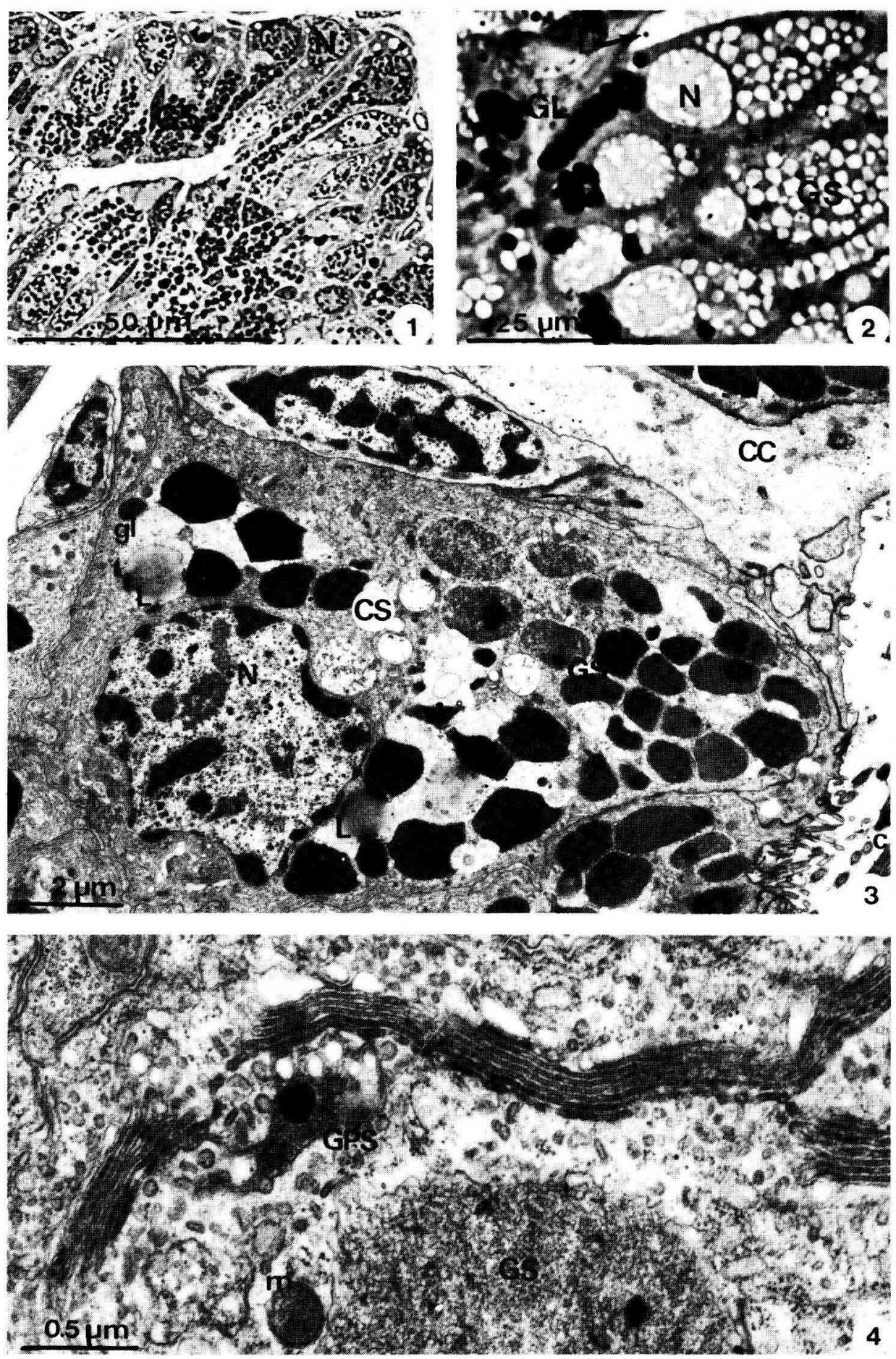
granuleux, sont en étroite relation avec les gouttelettes lipidiques. Cette zone basale de la cellule est particulièrement riche en mitochondries.

Le système endomembranaire développe également de longues citernes aplaties qui gagnent toute la région apicale de la cellule sécrétrice en s'insinuant entre les grains de sécrétion.

Le noyau des cellules sécrétrices s'éloigne de la région basale, il est plus ou moins arrondi, car il est légèrement comprimé latéralement. Son diamètre est inchangé ( 8 à $10 \mu \mathrm{m}$ ), par contre son contour est plus régulier ; la membrane externe de l'enveloppe nucléaire est tapissée de nombreux ribosomes et montre des relations de continuité avec les membranes du réticulum endoplasmique ( $\mathrm{PI}$. IV, fig. 1). La citerne périnucléaire est souvent dilatée ; l'espace ménagé entre les deux membranes, généralement de l'ordre de $50 \mathrm{~nm}$, atteint alors 80 à $120 \mathrm{~nm}$. L'hétérochromatine granulofilamenteuse reste très dense aux électrons ; elle est à la fois marginale et répartie en mottes d'une façon irrégulière dans le nucléoplasme. Elle entoure incomplètement le nucléole qui ménage un halo clair à sa périphérie. Les zones claires du nucléoplasme sont constituées d'euchromatine et de nombreux grains interchromatiniens $(20-25 \mathrm{~nm})$ qui peuvent être groupés en chaînettes. De grosses inclusions denses entourées de corps denses sont présentes, assez fréquemment, dans le nucléoplasme ; ces grains d'un diamètre de 80 à $120 \mathrm{~nm}$ pourraient représenter des enclaves protéiques ( $\mathrm{PI}$. IV, fig. 2).

L'appareil de Golgi, très comprimé par les grains de sécrétion, occupe une position supra-nucléaire latérale (PI. IV, fig. 3). Les saccules des dictyosomes, très allongés, parallèles aux membranes latérales, contiennent un matériel dense. La

\section{PLANCHE III}

FIG. 1. - Aspect d'un tubule de la prostate d'un Escargot de 6 mois $(\varnothing=20,5 \mathrm{~mm})$. Les cellules sécrétrices, au noyau volumineux (N) en position basale, renferment des grains de sécrétion (GS) colorés intensément en rouge (constitution protéique) ; la coloration de l'inclusion n'est pas constante; les gouttelettes lipidiques, non colorées, apparaissent très claires. Le cytoplasme des cellules ciliées est bleu clair (glycogène).

Coupe semi-fine dérésinée. Coloration : « stains all » $\mathrm{pH} 5,4$.

FIG. 2. - La plupart des gouttelettes de lipides (GL) sont concentrées dans la région basale des cellules sécrétrices. Dans les cellules ciliées, on observe également quelques inclusions lipidiques isolées $(\mathrm{L})$.

Animal âgé de 6 mois $(\varnothing=24 \mathrm{~mm})$. Coloration : noir soudan.

$\times 1100$

$\mathrm{N}$ : noyau.

FIG. 3. - Aspect ultrastructural de l'épithélium prostatique d'un Escargot âgé de 6 mois $1 \varnothing=22 \mathrm{~mm})$. Les cellules épithéliales devenues fonctionnelles (CS) acquièrent leur polarité : noyau (N) en position para-basale et grains de sécrétion (GS) en majorité dans la partie apicale. On notera la différence d'aspect des noyaux des cellules sécrétrices et des cellules ciliées (CC).

$\times 7000$

c : cil, gl : glycogène ; L : lipide.

FIG. 4. - Fragmentation du dernier saccule golgien et aspect fenestré d'un granule de prosécrétion (GPS) contenant une inclusion dense, sur la face de maturation d'un dictyosome.

Animal âgé de 6 mois $(\varnothing=25 \mathrm{~mm}$ ).

$\times 32000$

GS : grain de sécrétion ; $m$ : mitochondrie. 


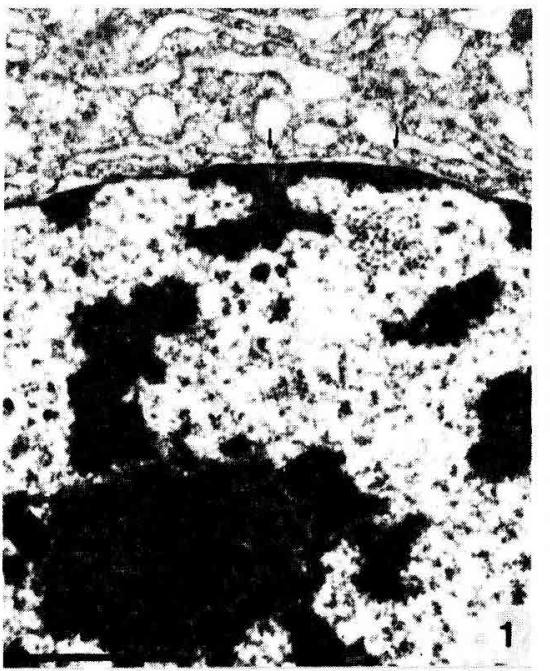

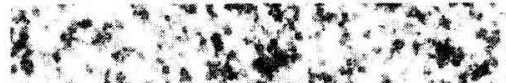

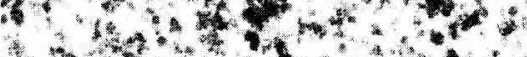

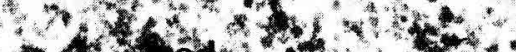

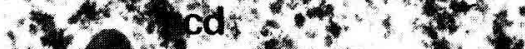

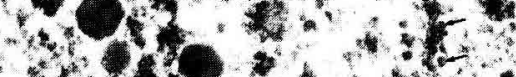
4t) 4.

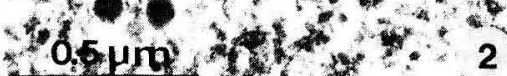

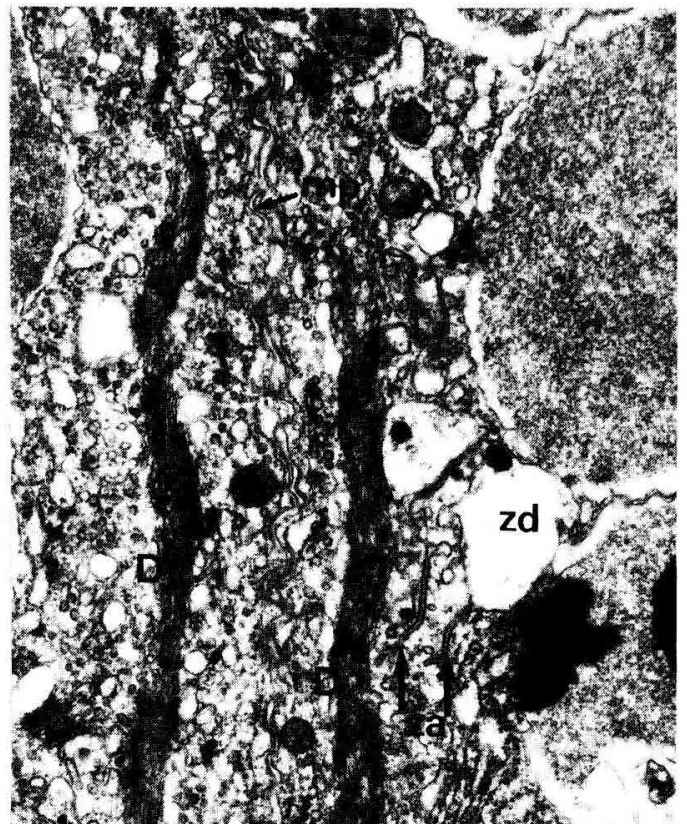

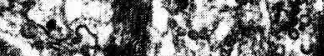

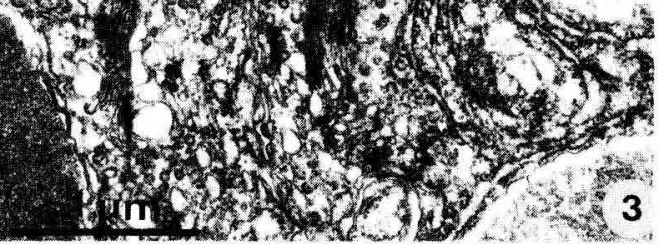

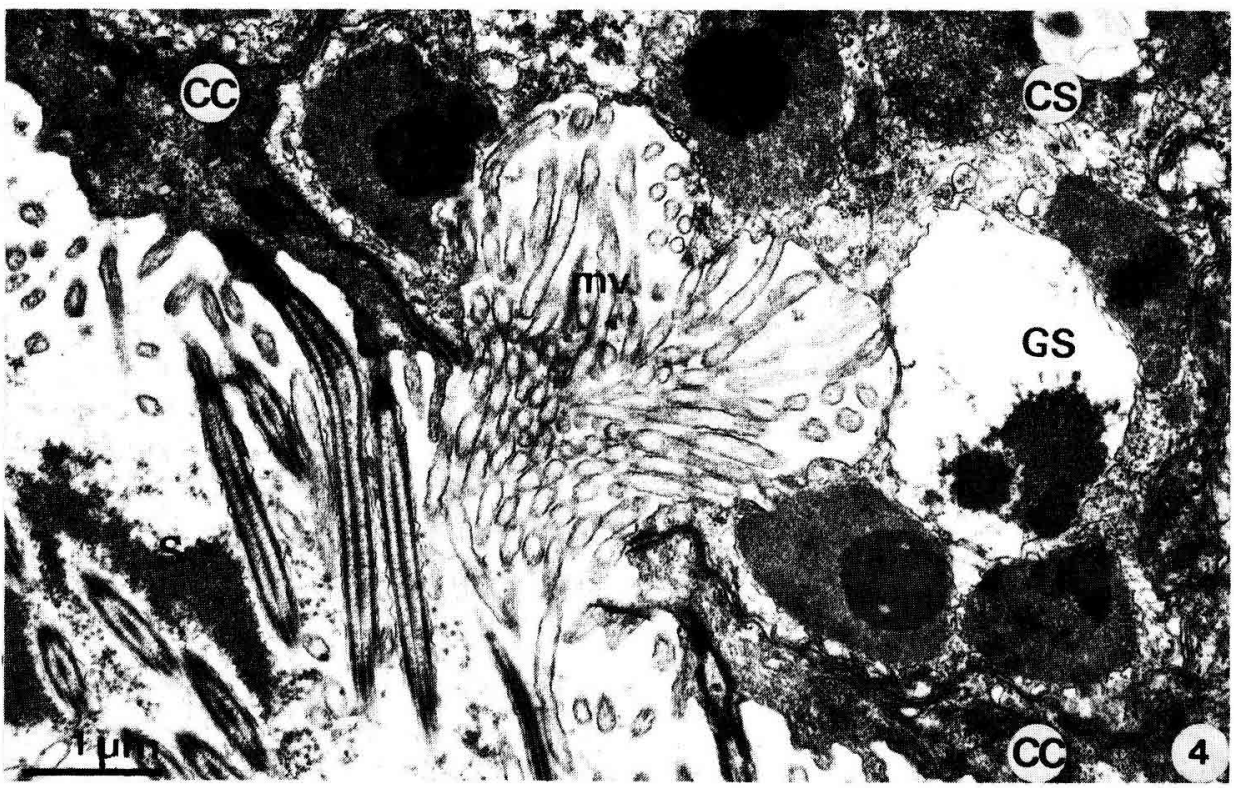


face de maturation est constituée de saccules dilatés qui se fragmentent pour donner naissance aux granules de prosécrétion. Ceux-ci comprennent une zone dilatée contenant une inclusion dense et une zone aplatie, à l'intérieur de laquelle « un matériel modérément dense forme de fines travées perpendiculaires aux parois" $)$.

Les grains de sécrétion, qui occupent la plus grande partie de la cellule, sont encore hétérogènes. L'inclusion dense, d'aspect pseudo-cristallin, est située au sein d'une matrice de densité variable aux électrons, mais qui est généralement plus claire que dans le stade précédent. Un matériel polymorphe et très dense est observé fréquemment en position marginale des grains de sécrétion et constitue des inclusions secondaires (PI. IV, fig. 3 et 4 ).

Au cours de cette phase de maturité, à l'apex des cellules sécrétrices, la membrane de quelques grains et la membrane plasmique entrent en contact (PI. IV, fig. 4), se soudent, puis le grain de sécrétion apparaît dans une invagination de la lumière limitée par une membrane (PI. V, fig. 1). L'excrétion est donc de type mérocrine. La membrane apicale, garnie de nombreuses microvillosités, est souvent en retrait de la lumière tubulaire proprement dite ; ceci conduit à la formation fréquente de petites cryptes (PI. IV, fig. 4) tapissées de microvillosités et bordées par l'extrémité apicale des cellules ciliées.

A ce stade, dans les cellules sécrétrices, le glycogène persiste sous forme de rares petites plages situées entre les grains de sécrétion ( $\mathrm{PI}$. V, fig. 2).

Les cellules ciliées s'étendent toujours de la lame basale à la lumière des tubules prostatiques, mais elles sont très comprimées par les cellules sécrétrices

\section{PLANCHE IV}

FIG. 1. - Noyau d'une cellule sécrétrice. L'hétérochromatine, très dense, entoure incomplètement le nucléole (n) qui ménage un halo clair à sa périphérie. Amas de particules (ribonucléoprotéiniques) de $25 \mathrm{~nm}$ dans les zones claires du nucléoplasme constituées d'euchromatine. Communication (flèches) entre la citerne périnucléaire et les cavités dilatées de l'ergastoplasme.

Animal âgé de 7 mois $(\varnothing=26,8 \mathrm{~mm})$.

FIG. 2. - Corps denses (cd) intranuc/éaires. Les grains interchromatiniens sont nombreux, épars dans le nucléoplasme ou disposés en chaînettes (flèches).

Animal âgé de 8 mois $(\varnothing=30 \mathrm{~mm}$ " bordé $»)$.

FIG. 3. - Dictyosomes (D) en position latérale de deux cellules sécrétrices adjacentes. A droite, sur la face de maturation du dictyosome, on distingue deux granules de prosécrétion présentant une zone dilatée claire (zd) contenant une inclusion dense, et une zone aplatie (za) à l'intérieur de laquelle on trouve un matériel sous forme de fines travées perpendiculaires aux parois. $\times 19000$ Animal âgé de 8 mois $(\varnothing=30,7 \mathrm{~mm}$ « bordé $)$ ).

$\mathrm{mp}$ : membrane plasmique.

FIG. 4. - Partie apicale d'une cellule sécrétrice (CS) entourée de deux cellules ciliées (CC). Affrontement de la membrane plasmique et de la membrane limitante des grains de sécrétion (GS). Zone de retrait de la membrane apicale constituant une crypte garnie de microvillosités (mv). Produits de sécrétion (S) dans la lumière du tubule prostatique. Animal âgé de 7 mois $(\varnothing=26,8 \mathrm{~mm})$. 

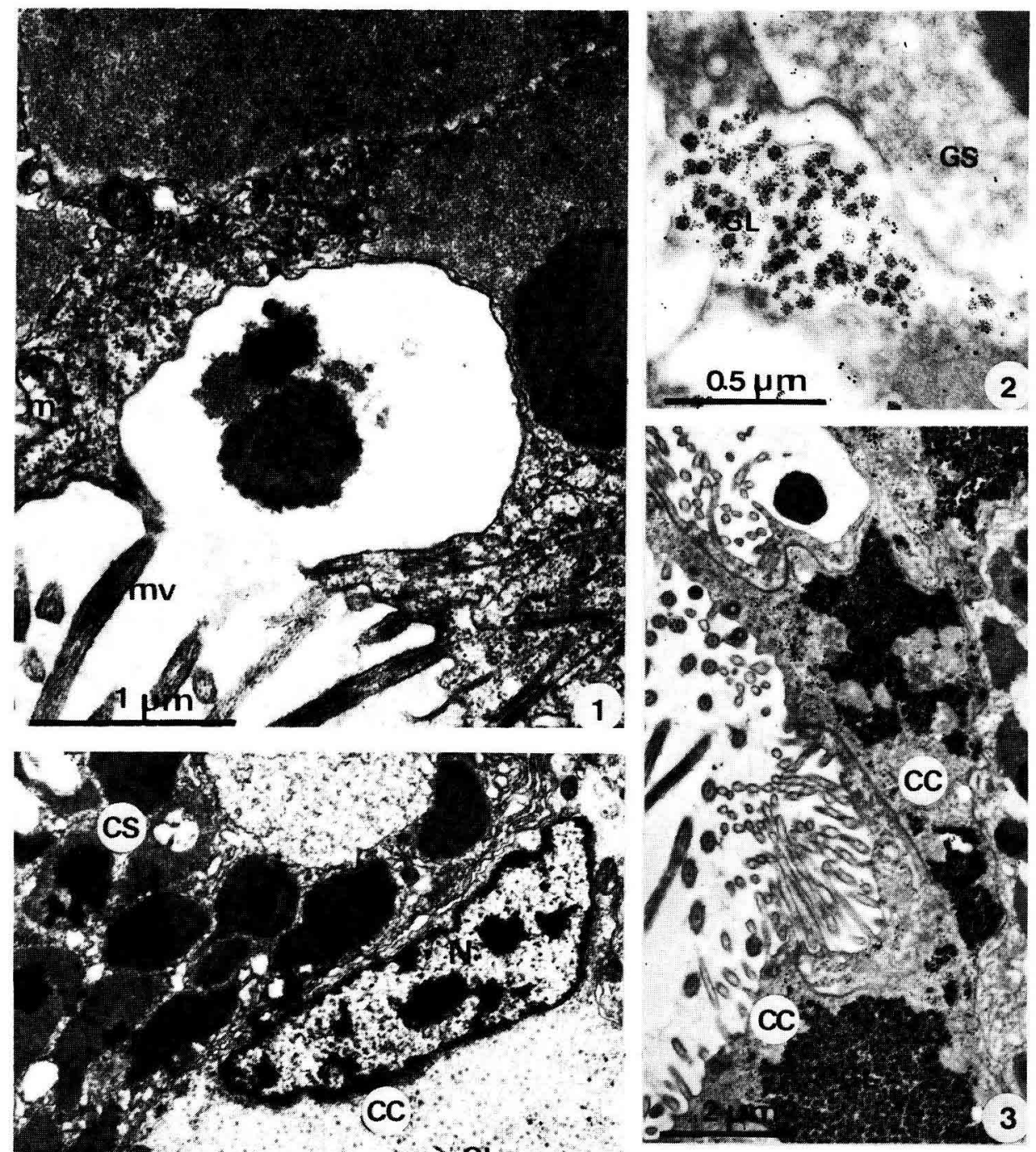

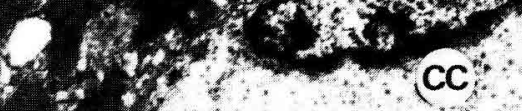

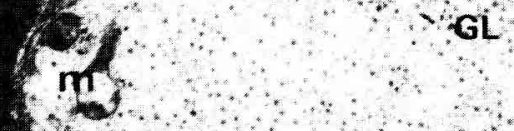

Gi

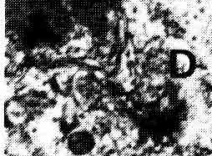

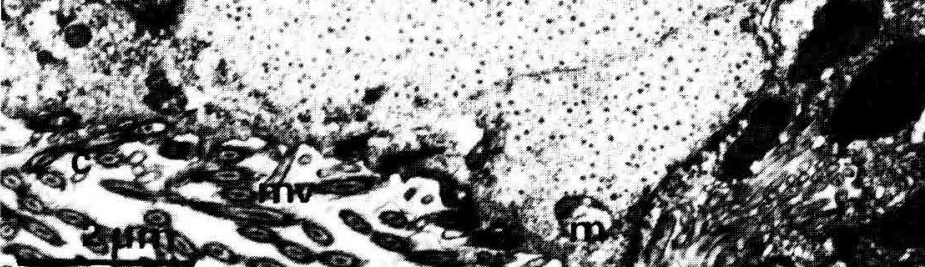

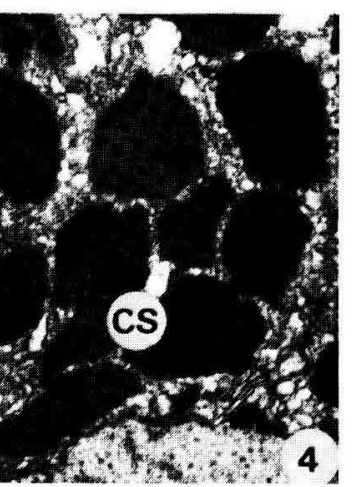


adjacentes. Le noyau occupe une position variable ; généralement placé dans une zone moyenne, on le trouve quelquefois dans la partie apicale des cellules (PI. V, fig. 4). Le réticulum endoplasmique granulaire est peu développé ; sous forme d'une nappe unique qui longe les membranes cellulaires et qui apparaît discontinue, il est observé plus fréquemment en regard de la face de formation des dictyosomes dont les saccules émettent des petites vésicules denses aux électrons. Le glycogène, sous forme de rosettes, mis en évidence par la méthode de Thiery et Rambourg (1974), est abondant dans tout le cytoplasme (PI. V, fig. 3). Les mitochondries et des corps multivésiculaires sont situés le plus souvent dans la zone apicale élargie. A cette extrémité de la cellule, on observe des microvillosités et une forte ciliature.

\section{Discussion.}

1. Origine et différenciation des cellules de la prostate.

La différenciation de la prostate de l'Escargot Helix aspersa qui se réalise à partir d'évaginations de l'épithélium du spermoviducte est comparable à celle qui a été décrite chez Limax maximus (Hoffmann, 1922) et chez Agriolimax agrestis (Filhol, 1938). Cependant, chez Agriolimax, Filhol (1938), Runham et Laryea (1968), Runham (1978) suggèrent que les cellules sécrétrices se différencient à partir d'éléments mésenchymateux s'infiltrant entre les cellules épithéliales. Au contraire, chez Helix aspersa, notre analyse ultrastructurale nous incite à croire que les cellules sécrétrices et les cellules ciliées dérivent du type épithélial, constituant les tubules prostatiques d'origine. Notons que la même conception

\section{PLANCHE V}

FIG. 1. - Excrétion mérocrine. Ouverture de la membrane plasmique et expulsion du contenu hétérogène d'un grain de sécrétion.

Animal âgé de 8 mois $(\varnothing=30 \mathrm{~mm}$ " bordé $»)$.

$\mathrm{m}$ : mitochondrie ; $\mathrm{mv}$ : microvillosités.

FIG. 2. - Mise en évidence du glycogène (GL) par la réaction PATAg dans les cellules sécrétrices. Quelques particules de glycogène sont soit éparses dans le cytoplasme, soit groupées en petites plages entre les grains de sécrétion (GS).

$\times 39000$

Animal âgé de 8 mois $(\varnothing=30,7 \mathrm{~mm}$ « bordé ").

FIG. 3. - Mise en évidence du glycogène (GL) par la réaction PATAg dans les cellules ciliées (CC). Sous forme de rosettes, il est abondant au pôle apical des cellules. Animal âgé de 7 mois $(\varnothing=26,8 \mathrm{~mm})$.

FIG. 4. - Zone apicale d'une cellule ciliée avec son noyau (N) allongé. Le glycogène (GL) est le constituant principal du cytoplasme; on observe un dictyosome (D) et des mitochondries (m). La membrane apicale est garnie de quelques microvillosités (mv) et de cils (c). $\quad \times 9000$ Animal âgé de 7 mois $(\varnothing=24 \mathrm{~mm})$. 
concernant l'origine des cellules de la glande à albumen a été retenue par Courtot et Gomot (1982).

L'accroissement considérable du volume cellulaire et nucléaire qui accompagne la différenciation d'une cellule sécrétrice provoque une forte extension de la cellule en direction du tissu mésenchymateux. Ainsi, sur certaines coupes parallèles ou tangentielles à un tubule prostatique, on peut rencontrer une ou plusieurs cellules sécrétrices isolées au sein du mésenchyme, et ce genre d'observation peut prêter à confusion quant à l'origine de cette catégorie cellulaire. Le principal argument retenu en faveur de l'origine épithéliale des cellules sécrétrices repose sur la présence de la lame basale qui circonscrit à la fois l'épithélium initial et les cellules sécrétrices volumineuses, au moment de la différenciation des premiers tubules. De plus, aucune infiltration de cellules mésenchymateuses dans l'épithélium n'ayant été observée à un stade précoce du développement du spermoviducte (Enée et Griffond, 1983), il apparaît que les cellules sécrétrices et les cellules ciliées se différencient à partir de l'épithélium de l'ébauche prostatique, composée de cellules indifférenciées, toutes identiques. Nos observations rejoignent celles de Yung (1911) et Quattrini (1967a) en ce qui concerne l'origine épithéliale des deux catégories cellulaires ; mais selon le dérnier auteur, les cellules ciliées représentent la structure d'origine et l'acquisition de l'activité sécrétrice s'accompagne de la perte des cils. Au contraire, notre étude ultrastructurale révèle l'absence de ciliogenèse dans les cellules sécrétrices et son existence dans les autres cellules épithéliales.

Dans les premiers tubules prostatiques de l'Escargot, les divisions des cellules épithéliales indifférenciées sont nombreuses. Au cours de l'organogenèse, l'observation de mitoses est moins fréquente et il est difficile de préciser la catégorie des cellules qui se divisent. Cependant, au cours de la période juvénile, on rencontre de nombreuses cellules non sécrétrices sans cils ; mise à part une ciliature très faible qui peut échapper à l'observation, il est possible que certaines cellules restent indifférenciées longtemps et continuent à se diviser en fournissant les cellules nécessaires au développement de la glande; en outre, on n'observe pas de cellules de réserve contre la lame basale.

La mise en place progressive de cellules sécrétrices et de cellules non sécrétrices ciliées dans l'épithélium des tubules ramifiés qui constituent la structure définitive de la prostate d'Helix aspersa est bien établie; les cellules sécrétrices sont situées intégralement dans les limites de l'épithélium et ne peuvent être confondues en aucun cas avec les cellules des glandes subépithéliales (fig. $3 \mathrm{~b}$ texte).

\section{Première phase sécrétoire de la prostate.}

a) Les cellules non sécrétrices ciliées. - La présence de cellules ciliées, riches en glycogène et intercalées entre les cellules sécrétrices, est fréquente dans les glandes sexuelles accessoires de plusieurs Invertébrés (Adiyodi et Adiyodi, 1975). Dans la prostate de l'Escargot, ces cellules s'étendent de la périphérie à la lumière des tubules glandulaires. L'alternance avec les cellules sécrétrices est irrégulière ; elles sont plus nombreuses dans les tubules proches du spermiducte 
où l'évacuation rapide des produits de sécrétion nécessite une action ciliaire efficace.

b) Les cellules sécrétrices. - La quasi-totalité du volume cytoplasmique des cellules sécrétrices est occupée par des grains de sécrétion hétérogènes. Les renseignements sur la nature des grains, obtenus par étude histochimique (Enée, 1980), révèlent que la constitution de la sécrétion prostatique est complexe. Une réaction légèrement positive au PAS montre qu'il existerait une composante glucidique qui n'a pas été confirmée en cytochimie ultrastructurale par la méthode de Thiery et Rambourg (1974). Les autres réactions histochimiques montrent que les grains de sécrétion contiennent deux constituants essentiellement protéiques qui ne sont pas mélangés. L'inclusion des grains, constituée de phospholipides et de protéines, figure au sein d'une matrice protéique. Les grains de sécrétion prostatique de la Sangsue Hirudo medicinalis étudiés par Pastisson (1968) sont également de nature mixte, protéique et phospholipidique, mais c'est la partie protéique du grain qui est entourée d'une zone claire de nature phospholipidique.

En ultrastructure, les cellules sécrétrices de la prostate d'Escargot présentent un ergastoplasme et un appareil de Golgi particulièrement développés comme cela a été décrit dans de nombreuses cellules sécrétrices (Jamieson et Palade, 1967a, b ; Neutra et Leblond, 1969 ; Sandoz et al., 1971 ; Jamieson et Palade, 1977 ; Courtot et Gomot, 1982). Un développement prééminent de l'ergastoplasme a été également signalé par De Jong-Brink (1969) dans la prostate de Biomphalaria, ce qui témoigne de l'intense activité de synthèse protéique de ces glandes.

L'acheminement des protéines vers l'appareil de Golgi se fait classiquement par de nombreuses vésicules de transition qui fusionnent avec le premier saccule golgien. La forte activité sécrétoire se traduit par un accroissement du diamètre des saccules qui est de l'ordre de 1 à 1,6 $\mu \mathrm{m}$ dans les cellules en différenciation et atteint 5 à $7 \mu \mathrm{m}$ dans les cellules en pleine activité sécrétrice. It semble qu'il n'existe pas de compartiments physiologiquement différents dans un même saccule, comme cela a été signalé dans les cellules des glandes multifides d'Escargot qui élaborent une sécrétion mixte composée de protéines et de glycoprotéines (Ovtracht et Thiery, 1972). Par contre, le dernier saccule observé sur la face de maturation des dictyosomes présente une grande similitude avec le sac post-golgien décrit dans les cellules des glandes multifides (Ovtracht et Thiery, 1978). Les saccules golgiens dilatés ressemblent aux "vacuoles de condensation " (Hand et Oliver, 1977; Novikoff et al., 1977) et évoluent en granule de prosécrétion qui renferme une inclusion dense au sein d'une matrice claire. Lorsque les granules de prosécrétion s'éloignent de la zone golgienne, ils confluent avec les vésicules golgiennes et constituent des grains de sécrétion dont le volume et la quantité de matériel de la matrice augmentent fortement. On observe également dans cette zone la confluence de formations tubulaires ayant l'aspect de saccules golgiens isolés (Hollande, 1972) ou de formations du réticulum endoplasmique (Novikoff et al., 1971 ; Dubois et Tachon, 1974 ; Hand et Oliver, 1977). Ainsi, certains constituants protéiques ou lipidiques pourraient participer à la constitution des grains de sécrétion sans transiter obligatoirement par l'appareil de Golgi bien que la liaison entre les protéines et le constituant lipidique puisse se réaliser dans les saccules golgiens (Claude, 1970), de même 
que la synthèse des phospholipides (Alliet, 1976). En phase de sécrétion abondante, on observe même la confluence de grains de sécrétion avec des enclaves cytoplasmiques de glycogène et de lipides.

Au cours de cette première phase sécrétoire de la prostate, nous avons observé la libération de quelques grains de sécrétion à l'apex des cellules. Toutefois, ce processus d'excrétion de type mérocrine est faible pendant la période qui précède la reproduction et la perte des grains est largement compensée par la poursuite de leur élaboration au niveau de l'appareil de Golgi. II s'ensuit une accumulation très importante de grains de sécrétion dans les cellules sécrétrices jusqu'au moment de l'accouplement qui s'accompagne de la décharge des cellules sécrétrices (Enée, 1980).

La différenciation de la prostate se caractérise donc par un développement précoce par rapport aux autres glandes annexes du tractus génital telles que la glande à albumen ou les glandes multifides, et il existe un synchronisme entre la phase organogénétique et la phase sécrétoire de cette glande mâle. De plus, on remarque une correspondance entre la différenciation des cellules prostatiques et le protandrisme de l'animal. Une observation comparable a été également faite chez divers Limacidés par Laviolette (1954) et chez Agriolimax reticulatus par Runham et al. (1973) qui ont démontré l'existence d'un facteur provoquant la différenciation de la prostate dans des conduits génitaux juvéniles greffés chez des Limaces dont la gonade est en phase mâle.

Reçu en mai 1983.

Accepté en mai 1984.

\section{Références}

ABDEL-MALEK E. T., 1954a. Morphological studies on the family Planorbidae (Mollusca: Pulmonata). I. Genital organs of Helisoma trivolvis Say (subfamily Helisomatinae F. C. Baker, 1945). Trans. amer. micr. Soc., 73, 103-124.

ABDEL-MALEK E. T., 1954b. Morphological studies on the family Planorbidae (Mollusca: Pulmonata). II. The genital organs of Biomphalaria boissyi (subfamily Planorbinae, H. A. Pilsbry, 1934\}. Trans. amer. micr. Soc., 73, 285-296.

ADIYODI K. G., ADIYODI R. G., 1975. Morphology and cytology of the accessory sex glands in Invertebrates. Intern. Rev. Cytol., 43, 353-398.

ALLIET J., 1976. La cellule et ses ultrastructures. Ouest médical, 29, 61-74.

ANDERSON W. A., ELLIS R. A., 1965. Ultrastructure of Trypanosoma lewisi : flagellum, microtubules and the kinetoplast. J. Protozool., 12, 483-499.

BAECKER R., 1932. Die Mikromorphologie von Helix pomatia und einigen anderen Stylommatophoren. Erg. Anat. Entwickl., 29, 449-585.

BAILEY T. G., 1973. The in vitro culture of reproductive organs of the slug Agriolimax reticulatus (Müll.). Neth. J. Zool., 23, 72-85.

BANI G., DELFINO G., 1974. Cellule globulari (o di Leydig) in alcune specie di Molluschi : aspetti al microscopio ottico, alcune immagini all' elettronico e considerazioni generali. Arch. ital. Anat. Embriol., 79, 115-135.

BAUDELOT M., 1863. L'appareil générateur des Mollusques Gastéropodes. Ann. Sci. nat. Zool., 19, 135-294.

BAYNE C. J., 1967. Studies on the composition of extracts of the reproductive glands of Agriolimax reticulatus, the grey field slug. Comp. Biochem. Physiol., 23, 761-773. 
BEEMAN R. D., 1970. The anatomy and functional morphology of the reproductive system in the Opistobranch Mollusk Phyllaplysia taylori Dall, 1900. The Veliger, 13, 1-31.

BREUCKER H., 1964. Cytologische Untersuchungen des Zwitterganges und des Spermoviduktes von Helix pomatia L. Protoplasma, 58, 1-41.

CARDNO S. S., STEINER J. W., 1965. Improvement of staining technics for thin sections of epoxy-embedded tissue. Amer. J. clin. Pathol., 43, 1-8.

CLAUDE A., 1970. Growth and differentiation of cytoplasmic membrane in the course of lipoprotein granule synthesis in the hepatic cell. I. Elaboration of elements of Golgi complex. J. Cell Biol., 47, 745-766.

COURTOT A. M., GOMOT L., 1982. Les stades de l'organogenèse et la cytodifférenciation de la glande à albumen de l'Escargot Helix aspersa Müller. Reprod. Nutr. Dévelop., 22, $661-680$.

CREEK G. A., 1951. The reproductive system and embryology of the snail Pomatias elegans (Müll.). Proc. Zool. Soc. Lond., 121, 599-639.

DUBOIS P., TACHON G., 1974. "GERL-complex », lysosomes et grains de sécrétion au cours de la différenciation cellulaire dans une glande endocrine chez l'Homme : l'antéhypophyse fœtale. J. Microscopie, 19, 253-264.

DUBRUEIL E., 1873. Etude physiologique sur l'appareil générateur du genre Helix. Rev. Sci. nat., $\mathbf{l}$.

DUNCAN C. J., 1975. Reproduction. In V. FRETTER, J. PEAKE, Pulmonates, 1, 309-365. Acad. Press, London/New York.

ENÉE J., 1980. Contribution à l'étude de la croissance de l'Escargot Helix aspersa Müller. Ontogenèse de l'appareil génital et recherche cytologique sur la différenciation et la sécrétion de la prostate. Thèse $3^{e}$ cycle, Besançon.

ENÉE J., GOMOT L., BRIDE M., 1977. Différenciation de la prostate chez l'Escargot Helix aspersa Müll. C. R. Soc. Biol., 171, 728-732.

ENÉE J., GRIFFOND B., 1983. Etude histologique et ultrastructurale de l'appareil génital postembrvonnaire d'Helix aspersa Müller. Reprod. Nutr. Dévelop., 23, 927-941.

FILHOL J., 1938. Recherches sur la nature des lépidosomes et les phénomènes cytologiques de la sécrétion chez les Gastéropodes Pulmonés. Arch. Anat. micr., 34, 155-218 et 375-439.

GODDARD C. K., 1960. A study of the reproductive tract of Helix aspersa Müller after partial gonadectomy. Austral. J. biol. Sci, 13, 378-386.

GOMOT L., ENÉE J., 1980. Biologie de la reproduction de l'Escargot Helix aspersa Müll. : les phases de croissance et la différenciation sexuelle. Atti Acad. Fisiocritici Siena, 73-85.

GREEN M. R., PASTEWKA J. V., 1974. Simultaneous differential staining by a cationic carbocyanine dye of nucleic acids, proteins and conjugated proteins. I. Phosphoproteins. J. Histochem. Cytochem., 22, 767-774.

GRIFFOND B., BRIDE J., 1981. Etude histologique et ultrastructurale de la gonade d'Helix aspersa Müller à I'éclosion. Reprod. Nutr. Dévelop., 21, 149-161.

GUYARD A., 1971. Etude de la différenciation de l'ovotestis et des facteurs contrôlant I'orientation sexuelle des gonocytes de l'Escargot Helix aspersa Müller. Thèse Dr ès Sci. Nat., Besançon.

GUYOMARCH-COUSIN C., 1976. Organogenèse descriptive de l'appareil génital chez Littorina saxatilis (Olivi), Gastéropode Prosobranche. Bull. Soc. Zool. Fr., 101, 465-476.

HAND A. R., OLIVER C., 1977. Relationship between the Golgi apparatus, GERL, and secretory granules in acinar cells of the rat exorbital lacrimal gland. J. Cell Biol., 74, 399-413.

HERLIN P., 1980. Contribution à l'étude de l'organogenèse post-larvaire de l'appareil génital mâle chez un Gastéropode Prosobranche gonochorique : Littorina littorea (L.). Thèse $3^{\mathrm{e}}$ cycle, Caen.

HOFFMANN H., 1922. Ueber die Entwicklung der Geschlechtorgane bei Limax maximus. Zeit. Wiss. Zool, 119, 493-536.

HOLLANDE E., 1972. Recherches expérimentales sur les glandes multifides de l'Escargot Helix pomatia L. Le cycle de l'appareil de Golgi pendant l'élaboration des mucoprotéines. Thèse Dr ès Sci. Nat., Paris VI.

HOLM L. W., 1946. Histological and functional studies on the genital tract of Lymnaea stagnalis appressa (Say). Trans. am. micr. Soc., 65, 45-68. 
HOUSTON R. S., 1976. The structure and function of neogastropod reproductive systems: with special reference to Columbella fuscata (Sowerby, 1832). The Veliger, 19, 27-46.

JAMIESON J. D., PALADE G. E., 1967a. Intracellular transport of secretory proteins in the pancreatic exocrine cell. I. Role of the peripheral elements of the Golgi complex. $J$. Cell Biol., 34, 577-596.

JAMIESON J. D., PALADE G. E., 1967b. Intracellular transport of secretory proteins in the pancreatic exocrine cell. II. Transport to condensing vacuole and zymogene granules. J. Cell Biol., 34, 597-615.

JAMIESON J. D., PALADE G. E., 1977. Production of secretory proteins in animal cells. In B. R. BRINKLEY, K. R. PORTER, International cell biology, The Rockfeller University Press (First int. Congr. on Cell Biology, Boston, Mass., 1976), 308-317.

JONG-BRINK M. de, 1969. Histochemical and electron microscope observations on the reproductive tract of Biomphalaria glabrata (Australorbis glabratus) intermediate host of Schistosoma mansoni. Z. Zellforsch., 102, 507-542.

JONG-BRINK M. de, 1973. The effects of dessiccation and starvation upon the weight, histology and ultrastructure of the reproductive tract of Biomphalaria glabrata, intermediate host of Schistosoma mansoni. Z. Zellforsch., 136, 229-262.

KUGLER O. E., 1965. A morphological and histochemical study of the reproductive system of the slug, Philomycus carolianus (Bosc). J. Morph., 116, 117-132.

LANE B. P., EUROPA D. L., 1965. Differential staining of ultrathin sections of epon-embedded tissues for light microscopy. J. Histochem. Cytochem., 13, 579-581.

LAVIOLETTE P., 1954. Rôle de la gonade dans le déterminisme humoral de la maturité glandulaire du tractus génital chez quelques Gastéropodes Arionidae et Limacidae. Bull. Biol. Fr. Bel., 88, 310-332.

LUFT J. H., 1961. Improvements in epoxy resin embedding methods. J. Biophys. Biochem. Cytol., 9, 409-414.

LUSIS O., 1961. Postembryonic changes in the reproductive system of the slug Arion ater rufus L. Proc. Zool. Soc. Lond., 137, 433-468.

MARSHALL A. T., 1973. Protein synthesis and secretion by the Malpighian tubules of Cercopoid larvae (Homoptera). J. Insect Physiol., 19, 2317-2326.

MOLLENHAUER H. H., 1964. Plastic embedding mixtures for use in electron microscopy Stain Technol., 39, 111-114.

McGEE-RUSSEL S. M., SMALE N. B., 1963. On colouring epon-embedded tissue sections with sudan black B or nile blue A for light microscopy. Quart. J. micr. Sci., 104, $109-115$.

NANAWARE S. G., VARUTE A. T., 1976. Histochemical studies on mucosubstances in the prostate gland of the pulmonate snail Semperula maculata in the annual breeding-aestivation cycle. Folia hist. Cyt., 14, 19-38.

NEUTRA M., LEBLOND C. P., 1969. The Golgi apparatus. Sci. Amer., 220, 100-107.

NOVIKOFF P. M., NOVIKOFF A. B., QUINTANA N., HAUW J. J., 1971. Golgi apparatus, GERL, and lysosomes of neurons in rat dorsal root ganglia, studied by thick section and thin section cytochemistry. J. Cell Biol., 50, 859-886.

NOVIKOFF A. B., MORI M., QUINTANA N., YAM A., 1977. Studies of the secretory process in the mammalian exocrine pancreas. I. The condensing vacuoles. J. Cell Biol., 75, 148-165.

OVTRACHT L., THIERY J. P., 1972. Mise en évidence par cytochimie ultrastructurale de compartiments physiologiquement différents dans un même saccule golgien. J. Microscopie, $15,135-170$.

OVTRACHT L., THIERY J. P., 1978. Différenciation zonale et transformation du saccule golgien issu de la face de maturation (sac post-golgien). Biol. cell., 32, 191-202.

PASTISSON C., 1968. Ultrastructure et histochimie de la prostate chez Hirudo medicinalis. Ann. Sci. Nat., 10, 151-162.

PLESCH B., JONG-BRINK M. de, BOER H. H., 1971. Histological and histochemical observations on the reproductive tract of the hermaphrodite pond snail Lymnaea stagnalis (L.). Neth. $J$. Zool., 21, 180-201.

QUATTRINI D., 1966a. Struttura e ultrastruttura della prostata dei Molluschi. I. Osservazioni in Vaginulus borellianus (Colosi) Gastropoda Soleolifera. Monit. Zool. Ital., 74, 1-30. 
QUATTRINI D., 1966b. Struttura e ultrastruttura della prostata dei Molluschi. II. Osservazioni in Laevicaulis a/te (Fèrussac) (Gastropoda Soleolifera). Monit. Zool. Ital., 74, 125-141.

QUATTRINI D., 1967a. Structure and ultrastructure of the molluscan prostate. 3. Observations on Milax gagates (Draparnaud) (Gastropoda Pulmonata Stylommatophora). Monit. Zool. Ital., 1. 109-128.

QUATTRINI D., 1967b. Structure and ultrastructure of the molluscan prostate. 4. Observations on Aplysia depilans Gmelin (Gastropoda Opisthobranchia). Monit. Zool. Ital., 1, 235-259.

QUATTRINI D., FONDI R., 1969. Structure and ultrastructure of the molluscan prostate. Observations on Veronicella s/oanei (Cuvier) (Gastropoda Soleolifera). Monit. Zool. Ital., 3, 117-133.

RANGARAO K., 1963. The polysaccharides of the reproductive system of the land snail Ariophanta ligulata in the formation of egg capsules. J. anim. Morph. Physiol., 10, 158-163.

REBHUN L. I., 1961. Some electron microscope observations on membranous basophilic elements of invertebrate eggs. J. U/trastruct. Res., 5, 208-225.

REYNOLDS E. S., 1963. The use of lead citrate at high $\mathrm{pH}$ as an electron opaque stain in electron microscopy. J. Cell Biol., 17, 208-212.

ROUZAUD H., 1885. Recherches sur le développement des organes génitaux de quelques Gastéropodes hermaphrodites. Thèse Sci., Montpellier Trav. Lab. Zool. Fac. Sci. Montpellier, 1. 1-133.

RUNHAM N. W., 1978. Reproduction and its control in Deroceras reticulatum. Malacologia, 17, 341-350.

RUNHAM N. W., LARYEA A. A., 1968. Studies on the maturation of the reproductive system of Agriolimax reticulatus. Malacologia, 7, 93-108.

RUNHAM N. W., BAILEY T. G., LARYEA A. A., 1973. Studies of the endocrine control of the reproductive tract of the grey field slug Agriolimax reticulatus. Malacologia, 14, 135-142.

SANDOZ D., ULRICH E., BRARD E., 1971. Etude des ultrastructures du magnum des Oiseaux. I. Evolution au cours du cycle de ponte chez la Poule Gallus domesticus. J. Microscopie, 11, 371-400.

SINGAL P. K., SANDERS E. J., 1974. Cytomembrane in first cleavage Xenopus embryos. Interrelationship between Golgi bodies, endoplasmic reticulum and lipid droplets. Cell Tiss. Res., 154, 189-209.

SMINIA T., 1972. Structure and function of blood and connective tissue cells of the fresh water pulmonate Lymnaea stagnalis studied by electron microscopy and enzyme histochemistry. Z. Zellforsch., 130, 497-526.

SMITH B. J., 1965. The secretions of the reproductive tract of the garden slug, Arion ater Ann. N. Y. Acad. Sci., 118, 997-1014.

SMITH B. J., 1966. Maturation of the reproductive tract of Arion ater (Pulmonata : Arionidae). Malacologia, 4, 325-349.

THIERY J. P., RAMBOURG A., 1974. Cytochimie des polysaccharides. J. Microscopie, 21, 225-232.

TRUMP B. F., SMUCKLER E. A., BENDITT E. P., 1961. A method for staining epoxy sections for light microscopy. J. U/trastruct. Res., 5, 343-345.

VELDHUIJZEN J. P., VAN BEEK G., 1976. The influence of starvation and of increased carbohydrate intake on the polysaccharide content of various body parts of the pond snail Lymnaea stagnalis. Neth. J. Zool., 26, 106-118.

VISSER M. H. C., 1977. The morphology and significance of the spermoviduct and prostate in the evolution of the reproductive system of the Pulmonata. Zoologica scripta, 6, 43-54.

VOSSWINKEL R., 1976. Das Blutgefässsystem von Helix pomatia L. (Gastropoda, Pulmonata). I. Makroskopische Untersuchung des arteriellen systems. Zool. Jb. Anat., 96, 529-554.

YUNG E., 1911. Structure de l'ovispermiducte et de la glande albuminipare chez l'Helix pomatia. C. R. Soc. Phys. Hist. nat. Genève, 32, 437-438. 